\title{
The Pathogenicity of Canine Parvovirus Type-2b, FP84 Strain Isolated from a Domestic Cat, in Domestic Cats
}

\author{
Koichiro GAMOH ${ }^{1)}$, Yohko SHIMAZAKI ${ }^{1)}$, Hirotaka MAKIE ${ }^{1)}$, Megumi SENDA ${ }^{1)}$, Osamu ITOH ${ }^{1)}$ and \\ Yoshimitu INOUE ${ }^{1)}$ \\ ${ }^{1)}$ National Veterinary Assay Laboratory, Ministry of Agriculture, Forestry and Fisheries, 1-15-1 Tokura, Kokubunji, Tokyo 185-8511, \\ Japan
}

(Received 17 February 2003/Accepted 15 May 2003)

ABSTRACT. Canine parvovirus type-2a (CPV-2a) and type-2b (CPV-2b) have recently been isolated from domestic cats. The pathogenicity of CPV-2b in domestic cats is still unclear. In this study, we performed infection tests to examine the pathogenicity of CPV-2b, FP84 strain, isolated from a domestic cat. The results demonstrated that the CPV strain FP84 is able to infect and replicate well in domestic cats. Two of the 3 cats used in the test died. They showed loss of appetite, diarrhea, leukopenia and dehydration. Since FP84 was found to be virulent to domestic cats, it is necessary to examine the efficacy of inactivated feline panleukopenia virus vaccines against CPV infection in domestic cats.

KEY WORDS: canine parvovirus, feline panleukopenia virus, pathogenicity.

J. Vet. Med. Sci. 65(9): 1027-1029, 2003

Canine parvovirus (CPV) is a pathogenic agent that causes severe hemorrhagic gastroenteritis in dogs. CPV was first isolated from a dog in 1978 in U.S.A. [1] and has since spread rapidly all over the world. The strain was designated CPV type-2 (CPV-2). After the appearance of CPV2 , new antigenic variants termed CPV type-2a (CPV-2a) and CPV type-2b (CPV-2b) were isolated [9, 10, 13]. CPV2 was completely replaced by CPV-2a and CPV-2b until 1985 [4, 9, 13]. CPV-2a and CPV-2b were recently isolated from domestic cats in Japan, Germany, U.S.A., Taiwan and Vietnam $[3,5-7,15,16]$. We previously reported that about $3 \%$ of parvovirus infections in domestic cats in Japan were caused by CPV-2a or CPV-2b [3].

The pathogenicity of CPV-2a and CPV-2b in domestic cats is still obscure. Nakamura et al. [8] reported that CPV2a had the potential to induce disease in cats. On the other hand, Sakamoto et al. [11] and Chalmers et al. [2] reported that CPV-2a and CPV-2b were able to infect cats but did not cause overt clinical signs. In this study, we examined the pathogenicity of FP84 strain, an isolate of CPV-2b from a domestic cat, in domestic cats.

CPV-2b strain FP84, which was isolated from a domestic cat in Tokyo in 2000 [3], was propagated by 4 passages in crandell feline kidney (CRFK) cells and prepared for the infection study. Three SPF domestic cats (American short hair, 18 weeks old, CSK Research Park, Nagano, Japan) were orally inoculated with $10^{6.7}$ TCID $_{50}$ of FP84. The clinical symptoms were recorded after inoculation. Because parvovirus infection causes various clinical signs, the scoring system [8] shown in Table 1 was used. Each domestic cat was bled before inoculation and on various days after inoculation to measure $\mathrm{HI}$ titers and the number of white blood cells (WBC). The method used for measurement of HI titers was described previously [12], and the total number of WBC was measured with a Celltac Automatic Analyzer
(Nihon Kohden, Tokyo, Japan).

Rectal swabs were taken to detect viral shedding. Swabs were diluted with $1 \mathrm{ml}$ of phosphate-buffered saline (PBS) containing $0.4 \%$ gentamysin. After centrifugation at 4,000 rpm for $10 \mathrm{~min}$ at $4^{\circ} \mathrm{C}, 100 \mu \mathrm{l}$ of each supernatant was inoculated to $5 \times 10^{5.0} / \mathrm{m} l$ of CRFK cell suspension in a $25 \mathrm{~cm}^{2}$

Table 1. Scoring system for symptoms of parvovirus infection ${ }^{\text {a) }}$

\begin{tabular}{cc}
\hline Symptom & Daily score \\
\hline Body temp $\left({ }^{\circ} \mathrm{C}\right)$ & \\
37.6 & 1 \\
$37.7-39.4$ & 1 \\
$39.5-39.9$ & 2 \\
$40.0-40.4$ & 3 \\
40.5 & \\
WBC counts ${ }^{\text {b }}$ & 1 \\
$59-40$ & 2 \\
$39-20$ & 3 \\
20 & 1 \\
Diarrhea & 2 \\
Mucoid & 3 \\
Fluid & 1 \\
Dysenteric & 1 \\
Loss of appetite & 1 \\
Vomiting & \\
Depression & 1 \\
Dehydration & 3 \\
Mild & 3 \\
Moderate & \\
Severe &
\end{tabular}

This table was quoted from Nakamura et al. [8]. a) When any of the indicated symptoms related to parvovirus were observed, scores were registered according to the point system outlined here. b) The WBC counts (per micro liter) of each cat are shown as the percentages of WBCs determined immediately prior to and after inoculation. 


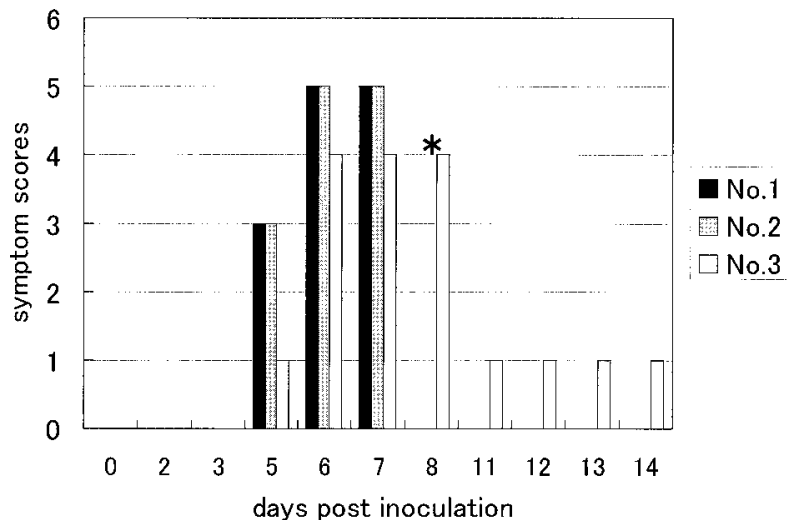

Fig. 1. Symptom scores from individual domestic cats inoculated with CPV-2b. *No.1 and No.2 were died on the 8th day post inoculation.

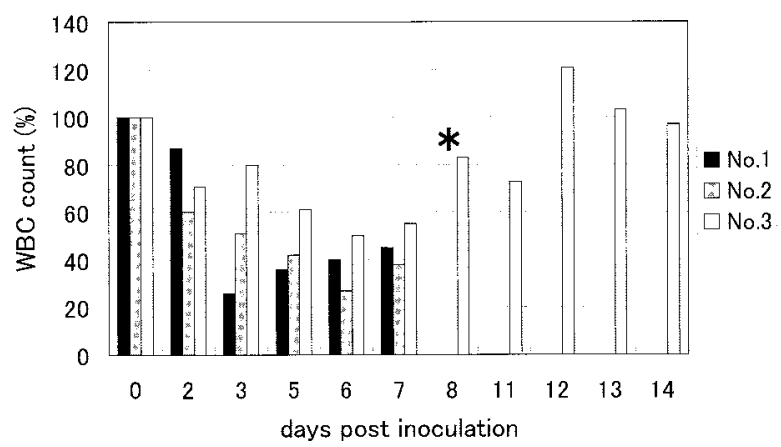

Fig. 2. WBC counts of domestic cats inoculated with CPV-2b. WBC counts are expressed as ratio (\%) to WBC counts at the time of inoculation. * No. 1 and No. 2 were died on the 8th day post inoculation.

flask and incubated at $37^{\circ} \mathrm{C}$. The culture fluid was exchanged on the following day and after incubation at $37^{\circ} \mathrm{C}$ for 6 days, the HA titer of the culture fluid was measured for detection of the virus.

In order to detect the virus in organs by PCR, samples were taken on the day of death or 15 days after inoculation. The thymus, heart, lung, liver, spleen, kidneys, mesenteric lymph nodes, duodenum, jejunum and ileum were homogenized to make $10 \%(\mathrm{w} / \mathrm{v})$ suspension with PBS. After centrifugation at $3,000 \mathrm{rpm}$ for $10 \mathrm{~min}$ at $4^{\circ} \mathrm{C}$, each sample was assayed by PCR for virus detection. The PCR primers and the condition for the detection of CPV-2a and CPV-2b were described previously [13].

After challenge with FP84, 2 cats (No. 1 and No. 2) died on the 8th day after inoculation. All of the domestic cats showed loss of appetite, leukopenia, diarrhea and dehydration but no vomiting or fever (Fig. 1). The mean WBC count reached the lowest level by the 7th day (Fig. 2). All of the domestic cats started viral shedding on the 5th day post inoculation (Fig. 3). The viral shedding in No. 1 and No. 2 cats reached the maximum level on the day of death, while

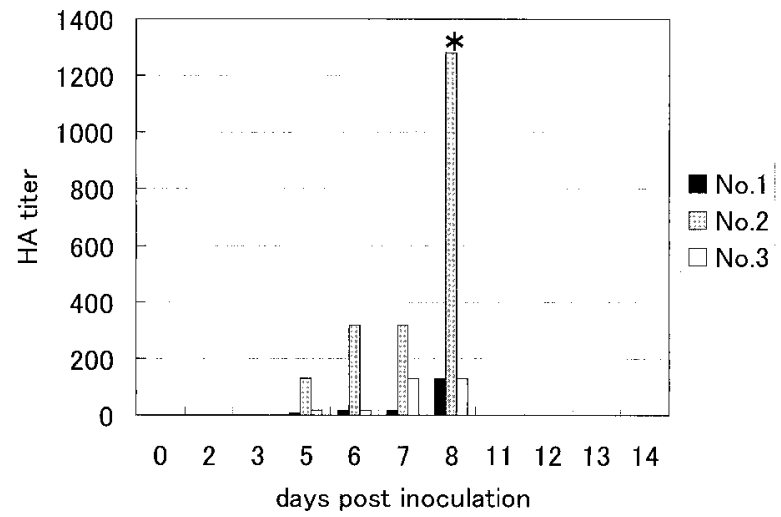

Fig. 3. HA titers of rectal swab from individual domestic cats inoculated with CPV-2b. * No. 1 and No. 2 were died on the 8th day post inoculation.

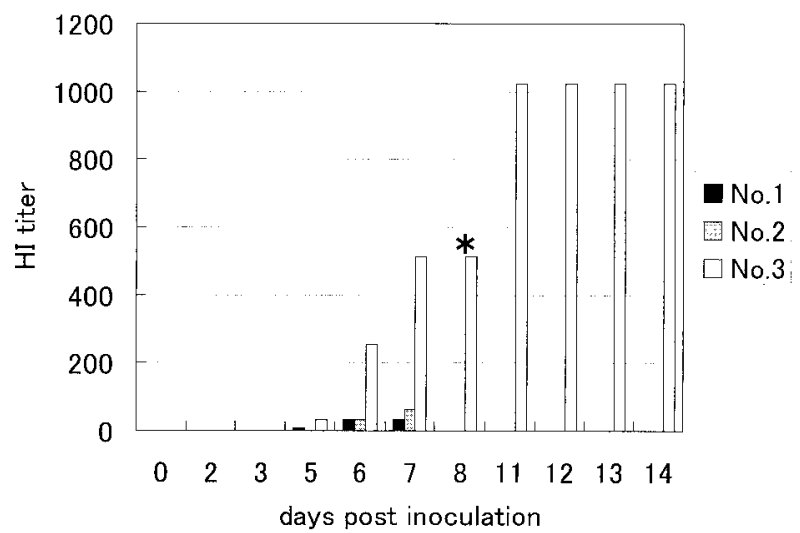

Fig. 4. HI titers of individual domestic cats inoculated with CPV2b. * No. 1 and No. 2 were died on the 8th day.

virus shedding in No. 3 cat, which survived, stopped on the 10th day. The viruses recovered from swabs were confirmed to be the inoculated virus by PCR and HI test using monoclonal antibodies [10] (data not shown). The HI antibody was first detected on the 5th or 6th day after inoculation, in all of the domestic cats. All of the domestic cats continued viral shedding even after the HI antibody had been detected.

Samples were taken from organs of the domestic cats for virus detection by PCR. The virus was detected in the samples taken from the heart, mesenteric lymph nodes, duodenum, jejunum and ileum of No. 1 and No. 2 cats, which died on the 8th day, while the virus was not detected in any samples taken from organs of No. 3 cat (Table 2).

This study demonstrated that FP84 strain was able to infect and replicate well in and was virulent to domestic cats. All of the domestic cats were infected with FP84 strain, shed the virus, and showed loss of appetite, diarrhea, leukopenia and dehydration. The result, together with previous studies, suggests that CPV-2b is circulating among the domestic cat population. 
Table 2. CPV-2b detection in organs by PCR

\begin{tabular}{lccc}
\hline & No. $1^{\text {a) }}$ & No. $2^{\text {b) }}$ & No. $3^{\text {c) }}$ \\
\cline { 2 - 4 } Thymus & - & - & - \\
Heart & + & + & - \\
Lung & - & - & - \\
Liver & - & - & - \\
Spleen & - & - & - \\
Kidney & - & - & - \\
Mesenteric lymph node & - & + & - \\
Duodenum & + & + & - \\
Jejunum & + & + & - \\
Ileum & + & + & - \\
\hline
\end{tabular}

a) No. 1 and b) No. 2 was died on 8 days post inoculation.

c) No. 3 was done euthanasia of 15 days post inoculation.

We previously reported that the proportions of CPV-2a and $\mathrm{CPV}-2 \mathrm{~b}$ in parvovirus infections in domestic cats in Japan were not so high [3]. However, considering the high prevalences of CPV-2a and CPV-2b infections in Taiwan and Vietnam [5], we are not able to deny the possibility that CPV-2a and CPV-2b are going to replace FPLV in domestic cats in the future. A live FPLV vaccine against CPV infection in domestic cats was confirmed to be effective [2], however, Steinel et al. [14] reported that inactivated FPLV vaccines are not always effective against CPV infection in domestic cats. Since the majority of FPLV vaccines used in Japan are inactivated vaccines, it is necessary to confirm the efficacy of inactivated FPLV vaccines against CPV infection in domestic cats.

ACKNOWLEDGEMENTS. The authors thank Dr. Collin R. Parrish, Cornell University, for providing monoclonal antibodies, Dr. Yukuharu Kobayashi, ADTEC Co., Ltd. for providing a feline isolate.

\section{REFERENCES}

1. Appel, M. J. G., Cooper, B. L., Greisen, H. and Carmichael, L. E. 1978. J. Am. Vet. Med. Assoc. 173: 1516-1518.

2. Chalmers, W. S. K., Truyen, U., Greenwood, N. M. and Baxendale, W. 1999. Vet. Microbiol. 69: 41-45.

3. Gamoh, K., Shimazaki, Y., Senda, M., Makie, H., Itoh, O. and Inoue, Y. 2003. Vet. Rec. (in press).

4. Gamoh, K., Senda, M., Shimazaki, Y., Makie, H., Inoue, Y. and Itoh, O. 2003. Vet. Rec. 152: 142-143.

5. Ikeda, Y., Mochizuki, M., Naito, R., Nakamura, K., Miyazawa, T., Mikami, T. and Takahashi, E. 2000. Virology 278: 13-19.

6. Mochizuki, M., Harasawa, R. and Nakatani, H. 1993. Vet. Microbiol. 38: 1-10.

7. Mochizuki, M., Horiuchi, M., Hiragi, H., SanGabriel, MC, Yasuda, N. and Uno, T. 1996. J. Clin. Microbiol. 34: 21012105.

8. Nakamura, K., Sakamoto, M., Ikeda, Y., Sato, E., Kawakami, K., Miyazawa, T., Tohya, Y., Takahashi, E., Mikami, T. and Mochizuki, M. 2000. Clin. Diag. Lab. Immun. 8: 663-668.

9. Parrish, C. R., O'Connell, P. H., Evermann, J. F. and Carmichael, L. E. 1985. Science 230: 1046-1048.

10. Parrish, C. R., Aquadro, C. F., Strassheim, M. L., Evermann, J. F., Sgro, J. -Y. and Mohammed, H. O. 1991. J. Virol. 65: $6544-6552$.

11. Sakamoto, M., Ishiguro, S. and Mochizuki, M. 1999. J. Jpn. Vet. Med. Assoc. 52: 305-309.

12. Senda, M., Hirayama, N., Yamamoto, H. and Kuraya, K. 1986. Vet. Microbiol. 12: 1-6.

13. Senda, M., Parrish, C. R., Harasawa, R., Gamoh, K., Muramatsu, M., Hirayama, N. and Itoh, O. 1995. J. Clin. Microbiol. 33: $110-113$

14. Steinel, A., Munson, L., Van Vuuren, M. and Truyen, U. 2000. J. Gen. Virol. 81: 345-350.

15. Truyen, U., Platzer, G. and Parrish, C. R. 1996. Vet. Rec. 138: 365-366.

16. Truyen, U., Evermann, J. F., Vieler, E. and Parrish, C. R. 1996. Virology 215: 186-189. 